\title{
Effect of lip position and gingival display on smile and esthetics as perceived by college students with different educational backgrounds
}

\author{
This article was published in the following Dove Press journal: \\ Clinical, Cosmetic and Investigational Dentistry \\ 30 October 2013 \\ Number of times this article has been viewed
}

\author{
Khalid H Zawawi ${ }^{1}$ \\ Ghadah A Malki \\ Mohammad S Al-Zahrani ${ }^{3}$ \\ Yaser M Alkhiary ${ }^{4}$ \\ 'Department of Preventive Dental \\ Science, Faculty of Dentistry, King \\ Abdulaziz University, ${ }^{2}$ Consultant \\ Pediatric Dentist, North Jeddah \\ Dental Specialty Center, ${ }^{3}$ Department \\ of Oral Basic and Clinical Sciences, \\ Faculty of Dentistry, ${ }^{4}$ Department of \\ Oral and Maxillofacial Rehabilitation, \\ Faculty of Dentistry, King Abdulaziz \\ University, Jeddah, Saudi Arabia
}

Aim: The aim of this study was to evaluate the influence of education on the perception of female college students on the effect of lip position and gingival display upon smiling and esthetics. Methods: A photograph of a smiling subject was altered to show varying degrees of gingival display. Female students, who were studying in different colleges, assessed a total of five images, using a numerical rating scale.

Results: A total of 440 college students from eight educational faculties (dentistry, dental assistants, medicine, medical technology, nursing, science, arts, and pharmacology) participated in this study. There was no difference found between students' ratings of the altered images $(P<0.05)$. The perception of a gummy smile was found to be similar among the participants. There was agreement between all participants that $2 \mathrm{~mm}$ of gingival display was the most attractive smile, while a $4 \mathrm{~mm}$ covering of the teeth by the upper lip was the least attractive.

Conclusion: Educational influence did not have an effect of the perception of a gummy smile.

Keywords: smile, gingival display, gummy smile, smile esthetic, perception, educational background

\section{Introduction}

Dental appearance is considered an important feature in determining the attractiveness of a face; thus, it influences human social interactions. ${ }^{1,2}$ The smile, in particular, plays a significant part in determining a first impression of an individual. ${ }^{3}$ Different factors affect the overall smile and esthetic, including tooth color, shape, position, quality of restoration, and general arrangement of the dentition, especially of the anterior teeth, upper lip position, visibility of teeth, and amount of gingival display. ${ }^{4}$ Although any factor could be considered separately, they are considered in concert and judged esthetically as a unit, in terms of symmetry and harmony. ${ }^{4}$

One variable considered as part of the smile analysis is the degree of gingival display and lip position, both at rest and while smiling. ${ }^{5,6}$ Excessive gingival display - so-called gummy smile - can render a smile as severe and unpleasant. However, the amount of gingival display considered attractive differs among various studies, ${ }^{5,7-11}$

A youthful smile is defined as full display of maxillary incisor crowns, with 1-2 mm of gingival margin. Usually, females tend to show 1-2 mm more of gingival tissue than males. ${ }^{12,13}$
Correspondence: Khalid H Zawawi Department of Preventive Dental Science, Faculty of Dentistry, King Abdulaziz University, PO Box 80209 , Jeddah 21589, Saudi Arabia

Tel +96626402000

Fax +96626403316

Email kzawawi@kau.edu.sa 
Recently, Silberberg et al ${ }^{14}$ showed that about $10 \%$ of their study population, aged between 20-30 years old, had gummy smiles, which were more evident in females than males, by a 2:1 ratio. A limited number of studies have compared the influence of educational background on perception of the smile. ${ }^{15,16}$

The aim of this study was to evaluate the effect of lip position and gingival display on smile and esthetics as perceived by college students with different educational backgrounds.

\section{Materials and methods}

Female students of King Abdulaziz University, Saudi Arabia, were asked to rate the attractiveness of a number of smiles, presented in a series of color photographs. Participants were enrolled from colleges of dentistry, dental assisting, medicine, medical technology, nursing, pharmacology, science, and the arts. The study was reviewed and approved by the University's Research Ethics Committee.

A smiling photograph of a 30 year old female subject was used in this study. She had healthy gingival and periodontal conditions, no dental spacing or crowding, and no apparent loss of tooth structure due to attrition, fracture, caries, or restoration. She had $4 \mathrm{~mm}$ of gingival display when smiling (Figure 1). The gingival display of the original image was digitally manipulated - using Adobe ${ }^{\circledR}$ Photoshop ${ }^{\circledR}$ version 7.01 (Adobe Systems Inc, San Jose, CA, USA) - to create a series of five images with different gingival displays, ranging from $4 \mathrm{~mm}$ of gingival display (to create a gummy smile) to $4 \mathrm{~mm}$ of tooth covering by the upper lip (Figure 1). The nose and chin were removed from the images to eliminate any confounding factors. The images were printed as glossy photographs (4 inches $\times$ 6 inches), and presented, in no set sequence, to each rater. A numerical rating scale (NRS) was used, where 0 was the rating for least attractive, and 10 was the rating for most attractive. The NRS has been shown to be an easy instrument to interpret, reliable, and useful. ${ }^{17}$

\section{Statistical analysis}

One-way analysis of variance tests (ANOVA) were conducted, between and within each group, to assess how participants rated each smile (which corresponded with a different level of gingival display). Overall tests for significance were followed by post hoc multiple comparisons between each level of gingival variation, to determine whether students of any college (educational influence) rated images differently; and also to determine which gingival display was perceived the most attractive, and which is the least attractive. Since variances were not homogenous, Dunnett's T3 method was used to perform post hoc multiple comparisons. Data analysis was performed using SPSS version 20 statistical software (IBM Corp, Armonk, NY, USA).

\section{Results}

A total of 440 female undergraduate college students participated in this study. Their mean age (with standard deviation) was $20.8 \pm 1.4$ years; there was no significant difference in age between colleges $(P>0.05)$.

Comparing the ratings of each smile between colleges using ANOVA, the results showed that ratings were similar in all colleges $(P>0.05)$ (Table 1).

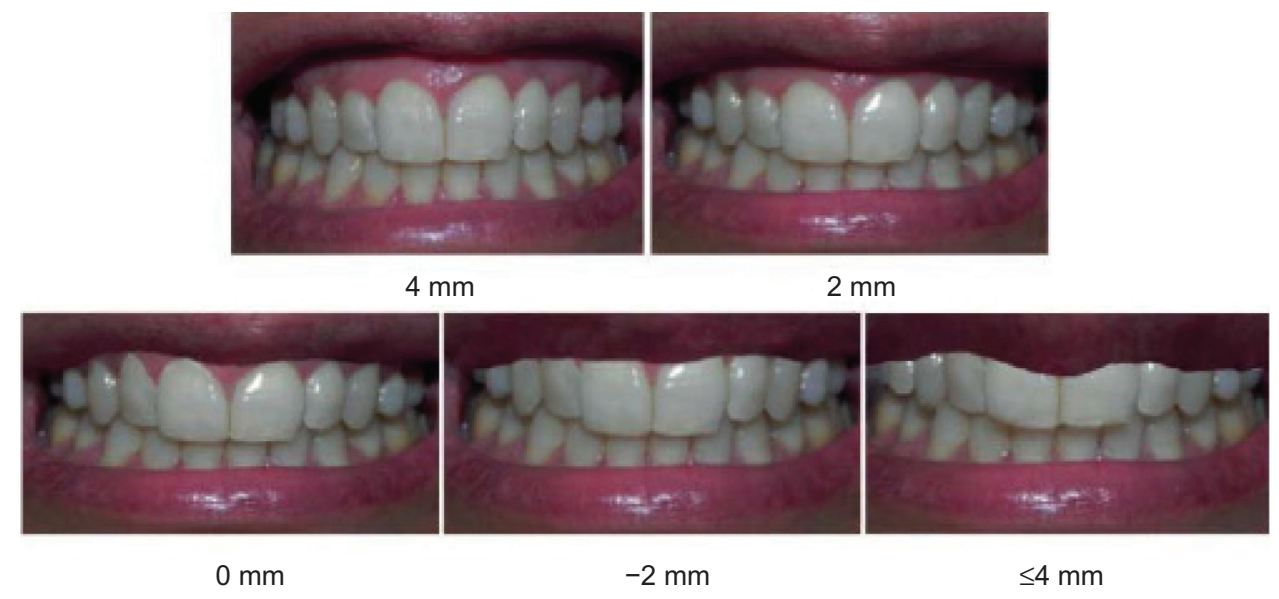

Figure I Gingival display.

Notes: Gingival display was increased or decreased by moving the upper lip. The smile was altered by 2 mm increments. The gingival margin between the maxillary central incisors was used a reference point. 
Table I Summary of comparisons between and within colleges for each image

\begin{tabular}{|c|c|c|c|c|c|c|}
\hline \multirow[t]{2}{*}{ College } & \multicolumn{6}{|c|}{ Gingival display } \\
\hline & $4 \mathrm{~mm}$ & $2 \mathrm{~mm}$ & $0 \mathrm{~mm}$ & $-2 \mathrm{~mm}$ & $\leq-4 \mathrm{~mm}$ & $P$-value* \\
\hline Dental $(n=50)$ & 5.2 & 7.0 & 6.2 & 5.6 & 3.7 & $<0.001$ \\
\hline Dental assistants $(n=90)$ & 5.4 & 7.6 & 6.8 & 5.1 & 3.5 & $<0.001$ \\
\hline Medicine $(n=50)$ & 6.3 & 8.1 & 6.7 & 5.4 & 4.6 & $<0.001$ \\
\hline Pharmacology $(n=50)$ & 6.0 & 7.2 & 6.3 & 5.0 & 3.7 & $<0.001$ \\
\hline Medical technology $(n=50)$ & 5.9 & 7.8 & 7.1 & 5.7 & 4.4 & $<0.001$ \\
\hline Nursing $(n=50)$ & 5.5 & 7.4 & 6.7 & 5.8 & 4.4 & $<0.001$ \\
\hline Science $(n=50)$ & 5.5 & 7.1 & 6.6 & 5.6 & 3.8 & $<0.001$ \\
\hline Arts $(n=50)$ & 5.9 & 7.1 & 6.7 & 5.8 & 4.9 & $<0.001$ \\
\hline$P$-value** & 0.4 & 0.17 & 0.64 & 0.69 & 0.09 & \\
\hline
\end{tabular}

Notes: *Comparison between ratings within each college; **comparison between college ratings.

When comparing each smile rating within each group of colleges, ANOVA showed that the ratings of the smile images were significantly different $(P<0.001)$. As shown in Table 1, the highest mean rating was for the smile with $2 \mathrm{~mm}$ of gingival display, for all students, and the lowest rating was for the smile with $4 \mathrm{~mm}$ or more of upper lip covering the maxillary incisors.

Since the ratings for each image were not significantly different between colleges, the total sample was treated as one group (Figure 2).

\section{Discussion}

This study aimed to evaluate the influence of education on the esthetic perceptions of female university students of the effect of lip position and gingival display on smiling. It was found that all students, regardless of their college of training, scored each smile image similarly. Interestingly, dental students, and dental assistant students, did not rate smile images differently than students of other colleges. Incisor lip

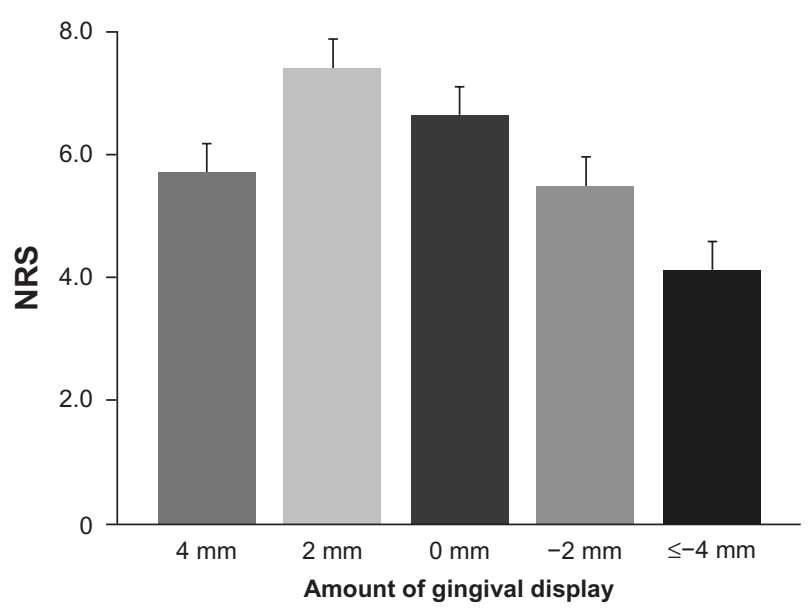

Figure 2 Combined mean scores of the numerical rating scale (NRS) for each image for all colleges. coverage was considered unattractive, which has not been addressed by previous studies. Furthermore, all participants agreed that when the upper lip covered the upper incisors by $4 \mathrm{~mm}$, it created an unattractive smile, which has not been shown in previous studies.

Earlier studies have reported different findings with respect to an attractive smile. A study by Geron and Atalia ${ }^{10}$ found that a $1 \mathrm{~mm}$ display of upper gingiva during smiling was considered unattractive, while lip coverage of the upper incisors between $0-2 \mathrm{~mm}$ was found to be the most pleasing esthetically. In another study, Hunt et $\mathrm{al}^{8}$ also found that $0 \mathrm{~mm}$ of gingival display was the most attractive, and that $3 \mathrm{~mm}$ of gingival display had the lowest score for attractiveness. Kokich et $\mathrm{al}^{7}$ compared the perceptions of dental professionals and lay people. Both groups agreed that $3 \mathrm{~mm}$ of gingival display resulted in an unattractive smile. The study concluded that there was no difference between lay people and dentists in their perceptions of gummy smile. Another study showed that $4 \mathrm{~mm}$ of gingival display was rated by dentists as unattractive. ${ }^{9}$ A study by Jornung and Fardal ${ }^{15}$ found that dentists are more precise at assessing gingival display, compared to lay people. The lay people who participated in these studies included businesspeople, attorneys, teachers, social science students, assorted workers, and patients, who provided opinion of their own smiles. ${ }^{7,8,15}$ In contrast, the current study investigated how students from different educational settings perceived smiles. Only female students were selected, to eliminate any gender bias. ${ }^{10}$ The results showed agreement between all college students. Two millimeters of gingival display was found in the most attractive smile, while $4 \mathrm{~mm}$ of lip coverage of the upper incisors was found in the least attractive smile. The participants' different educational settings did not influence how they rated the smile esthetically. This finding is not in agreement with earlier findings of studies conducted in different populations. ${ }^{7-10,15}$ This 
could be attributed to differences in participants' cultural backgrounds.

The results of this study could be helpful for management of patients with excessive gingival display. The gingival display can be considered, in conjunction with parameters such as tooth width-to-length ratios of the anterior teeth, by the esthetic dentist, orthodontist, and periodontist, in determining appropriate treatment.

\section{Conclusion}

Their different educational backgrounds did not influence female college students' perceptions of the effect of lip position and gingival display on the esthetics of smiling. Two millimeters of gingival display was considered the most attractive, while $4 \mathrm{~mm}$ lip coverage of the incisors was considered the least attractive smile.

\section{Acknowledgments}

The authors would like to thank Abeer Abdullah, Afaf H Alsulami, Mashael A Foudah, and Meaad A Mogaddam for their valuable assistance during data collection.

\section{Disclosure}

The authors report no conflicts of interest in this work.

\section{References}

1. Newton JT, Prabhu N, Robinson PG. The impact of dental appearance on the appraisal of personal characteristics. Int J Prosthodont. 2003;16(4):429-434.

2. York J, Holtzman J. Facial attractiveness and the aged. Spec Care Dentist. 1999;19(2):84-88.

3. Tjan AH, Miller GD, The JG. Some esthetic factors in a smile. J Prosthet Dent. 1984;51(1):24-28.
4. Qualtrough AJ, Burke FJ. A look at dental esthetics. Quintessence Int. 1994;25(1):7-14.

5. Jorgensen MG, Nowzari H. Aesthetic crown lengthening. Periodontol 2000. 2001;27:45-58.

6. Takei HH, Bevilacqua F, Cooney J. Surgical crown lengthening of the maxillary anterior dentition: aesthetic considerations. Pract Periodontics Aesthet Dent. 1999;11(5):639-644; quiz 646.

7. Kokich VO Jr, Kiyak HA, Shapiro PA. Comparing the perception of dentists and lay people to altered dental esthetics. J Esthet Dent. 1999;11(6):311-324.

8. Hunt O, Johnston C, Hepper P, Burden D, Stevenson M. The influence of maxillary gingival exposure on dental attractiveness ratings. Eur $J$ Orthod. 2002;24(2):199-204.

9. Kokich VO, Kokich VG, Kiyak HA. Perceptions of dental professionals and laypersons to altered dental esthetics: asymmetric and symmetric situations. Am J Orthod Dentofacial Orthop. 2006;130(2):141-151.

10. Geron S, Atalia W. Influence of sex on the perception of oral and smile esthetics with different gingival display and incisal plane inclination. Angle Orthod. 2005;75(5):778-784.

11. Al-Jabrah O, Al-Shammout R, El-Naji W, Al-Ajarmeh M, Al-Quran AH. Gender differences in the amount of gingival display during smiling using two intraoral dental biometric measurements. J Prosthodont. 2010;19(4):286-293.

12. Gill DS, Naini FB, Tredwin CJ. Smile aesthetics. Dent Update. 2007;34(3):152-154, 157-158.

13. Al-Habahbeh R, Al-Shammout R, Al-Jabrah O, Al-Omari F. The effect of gender on tooth and gingival display in the anterior region at rest and during smiling. Eur J Esthet Dent. 2009;4(4):382-395.

14. Silberberg N, Goldstein M, Smidt A. Excessive gingival display etiology, diagnosis, and treatment modalities. Quintessence Int. 2009;40(10):809-818.

15. Jornung J, Fardal O. Perceptions of patients' smiles: a comparison of patients' and dentists' opinions. J Am Dent Assoc. 2007;138(12): 1544-1553; quiz 1613-1614.

16. Peck S, Peck L, Kataja M. The gingival smile line. Angle Orthod. 1992;62(2):91-100; discussion 101-102.

17. Magnusson T, List T, Helkimo M. Self-assessment of pain and discomfort in patients with temporomandibular disorders: a comparison of five different scales with respect to their precision and sensitivity as well as their capacity to register memory of pain and discomfort. J Oral Rehabil. 1995;22(8):549-556.
Clinical, Cosmetic and Investigational Dentistry

\section{Publish your work in this journal}

Clinical, Cosmetic and Investigational Dentistry is an international, peer-reviewed, open access, online journal focusing on the latest clinical and experimental research in dentistry with specific emphasis on cosmetic interventions. Innovative developments in dental materials, techniques and devices that improve outcomes and patient satisfac-

\section{Dovepress}

tion and preference will be highlighted. The manuscript management system is completely online and includes a very quick and fair peerreview system, which is all easy to use. Visit http://www.dovepress. com/testimonials.php to read real quotes from published authors. 